\title{
Effect of shared decision making on mode of delivery and decisional conflict and regret in pregnant women with previous cesarean section: a randomized clinical trial
}

Fatemeh Hadizadeh-Talasaz ${ }^{1}$, Faezeh Ghoreyshi ${ }^{2}$, Fatemeh Mohammadzadeh ${ }^{3}$ and Roghaieh Rahmani ${ }^{*}$

\begin{abstract}
Background: The promotion of vaginal birth after cesarean section (VBAC) is the best method for the reduction of repeated cesarean sections. Nonetheless, the decisional conflict which often results from inadequate patient involvement in decision making, may lead to delayed decision making and regret about the choices that were made. The present study aimed to determine the effect of shared decision making on the mode of delivery and decisional conflict and regret in pregnant women with previous cesarean section.

Methods: This randomized clinical trial was conducted on 78 pregnant women with a previous cesarean section referring to community health centers in Torbat-e Jam, Iran, in 2019. They were randomly assigned to two groups of intervention and control. During weeks 24-30 of pregnancy, the Decisional Conflict Scale (DCS) was completed by pregnant mothers. Apart from the routine care, the experimental group received a counseling session which was held based on the three-talk model of shared decision making. This session was moderated by a midwife; moreover, a complementary counseling session was administered by a gynecologist. During weeks 35-37 of pregnancy, DCS was completed, and the Decision Regret Scale (DRS) was filled out for both groups at the 8th weeks postpartum and they were asked about the mode of delivery. Data were analyzed in SPSS software (version 19) using the Mann-Whitney, Chi-squared and Fisher's exact tests. $p$-value less than 0.05 was considered statistically significant.
\end{abstract}

Results: After the intervention, the decisional conflict score was significantly lower in the shared decision making (SDM) group, compared to that in the control group (14.90 \pm 9.65 vs. $25.41 \pm 13.38$; $P<0.001)$. Moreover, in the SDM group, the rate of vaginal birth was significantly higher than that in the control group $(P<0.001)$. Two month after the delivery, the mean score of decision regret was lower in the SDM group, in comparison to that in the control group (15.67 \pm 23.37 vs. $27.30 \pm 26.75 ; P=0.007)$.

(Continued on next page)

\footnotetext{
*Correspondence: roghaiehrahmany@yahoo.com; journal_2018@yahoo.com 'Department of Midwifery, Faculty of Medicine, Social Development \& Health Promotion Research Center, Gonabad University of Medical Sciences, Gonabad, Iran

Full list of author information is available at the end of the article
}

(c) The Author(s). 2021 Open Access This article is licensed under a Creative Commons Attribution 4.0 International License, which permits use, sharing, adaptation, distribution and reproduction in any medium or format, as long as you give appropriate credit to the original author(s) and the source, provide a link to the Creative Commons licence, and indicate if changes were made. The images or other third party material in this article are included in the article's Creative Commons licence, unless indicated otherwise in a credit line to the material. If material is not included in the article's Creative Commons licence and your intended use is not permitted by statutory regulation or exceeds the permitted use, you will need to obtain permission directly from the copyright holder. To view a copy of this licence, visit http://creativecommons.org/licenses/by/4.0/. The Creative Commons Public Domain Dedication waiver (http://creativecommons.org/publicdomain/zero/1.0/) applies to the data made available in this article, unless otherwise stated in a credit line to the data. 
(Continued from previous page)

Conclusions: Based on the results of the study, shared counseling can be effective in the reduction of decisional conflict and regret, as well as rate enhancement of VBAC. Therefore, it can be concluded that this counseling method can be used in prenatal care to reduce the rate of repeated cesarean section.

Trial registration: IRCT20190506043499N1; Name of the registry: Iranian Registry of Clinical Trials; Registered 10. August 2019. URL of registry: https://en.irct.ir/trial/39538. Date of enrolment of the first participant to the trial: August 2019.

Keywords: Shared decision making, Vaginal birth after cesarean, Repeated cesarean section, Conflict, Regret

\section{Background}

The increasing rate of cesarean section has evoked a global health concern. As evidenced by the recent data, approximately $50 \%$ of cesarean sections are performed selectively, and the majority of these operations are due to repeated cesarean section [1]. The promotion of vaginal birth after cesarean (VBAC) for eligible women and rate enhancement of successful VBACs are the best methods for the reduction of repeated cesarean sections [2]. Although ample evidence demonstrated that VBAC is a safe mode of delivery for most women, and 3 out of 4 women may be successful, VBAC rates are declining [1].

The rate of trial of labor after cesarean (TOLAC) and VBAC vary widely across the globe [3]. VBAC rates were reported as $29-36 \%$ in Ireland, Italy, and Germany, 45$55 \%$ in Finland, Sweden, and the Netherlands, $14 \%$ in Australia [4], and $13.3 \%$ in the United States [5]. The Healthy People 2020 goals include an increase in VBAC to $18.3 \%[6,7]$. Decision making regarding the mode of delivery (e.g., vaginal birth or cesarean section) is one of the most challenging decisions for pregnant mothers and the medical team. Due to the complex nature of decision making process, appropriate and effective tools are needed to improve and facilitate decision making. These tools can involve pregnant women in decision making, increase information, and reduce concerns [8]. One of these tools is shared decision making (SDM) which is a dynamic and interactive process in which the patient and health care providers share information. In so doing, they can have shared treatment decision making based on the best available evidence, as well as patient values and preferences [9-12].

Patients' participation and awareness of their preferences improve the quality of care and treatment outcomes [13]. The results of a systematic review (2007) demonstrated that patients with greater participation in treatment decisions were more informed of their options and had realistic expectations about what might happen. Moreover, the majority of them selected the option which was most valuable to them [14]. Previous data suggested that the degree of decisional conflict experienced by patients may be affected by the degree of shared decision making in patient counseling. The patients who experience more SDM will have less decisional conflict [15].

Decisional conflict in patients often results from insufficient patient involvement in decision making, which may lead to delayed decision making and decision regret [16]. Shared decision making using decision aids is one of the techniques for the reduction of decision conflict in primary care. Decision regret can also potentially be modified through shared decision making [17]. Hong et al. (2016) suggested that more involvement in decision making process will reduce decisional conflict and regret [11].

Shared decision making can help and facilitate decision making; nonetheless, no study was retrieved from databases on the impact of shared decision making on decisional conflict and regret in pregnant women with a previous cesarean section in Iran. According to the aforementioned issues, the present study aimed to determine the effect of shared decision making on mode of delivery and decisional conflict and regret in women with a previous cesarean section.

\section{Methods}

This randomized clinical trial with two parallel groups (intervention and control groups) was performed on pregnant women in Torbat-e Jam, Iran, from August 2019 to March 2020. The minimum sample size was calculated at 78 subjects; however, a total of 86 cases $(n=$ 43 in each group) were entered into the study considering $10 \%$ sample attrition. This calculation was performed based on a similar study [18], the mean difference formula, as well as considering the effect size $d=0.75$, type I error of 0.05 , and the test power of $80 \%$ using $G^{*}$ Power software (version 3.1.9.2). The sample size was calculated for both conflict and regret variables, and finally, a larger sample size was considered.

The inclusion criteria were as follows: 1) women with singleton pregnancies with live fetuses, 2) absence of fetal anomalies, 3) no medical problems (including diabetes, hypertension, as well as heart, liver, and kidney disease), 4) history of only one previous cesarean section, 5) previous transverse cesarean scar, 6) absence of 
contraindication to vaginal delivery in current pregnancy (large fetus, stable placenta previa, multiple births, polyhydramnios and oligohydramnios, eclampsia and preeclampsia, rupture of membrane, unreliable fetal condition, non-cephalic presentation), 7) gestational age of 20-30 weeks, 8) interval between the previous delivery and the first day of the last menstrual period of the current pregnancy more than 6 months, 9) waiting to give birth in 37 weeks or more, 10) absence of mental illness, and 11) non-reception of written advice other than the usual counseling of the center. On the other and, the exclusion criteria entailed: 1) unwillingness to continue cooperation, 2) occurrence of medical or obstetric contraindications to vaginal delivery, 3) delivery before the end of the study period, 4) absence in any of the two counseling sessions, 5) participation in other counseling sessions other than the usual counseling of the center, and 6) incomplete questionnaires in any of the follow-up stages.

Data collection tools included: demographic and obstetric profile questionnaire, Decisional Conflict Scale (DCS) developed by O'Connor, Decision Regret Scale (DRS), and a question about the mode of delivery .

DCS is a 16-item self-report questionnaire with five subscales, including informed, values clarity, social support, uncertainty, and effective decision [19]. Participants respond to each item using a 5-point Likert scale ranging from 0 (strongly agree) to 4 (strongly disagree). In each of the subdomains or subscales, firstly, the scores of the items are summed up, divided by the number of items, and multiplied by 25 . The total score ranges from 0 to 100 . A score below 25 means the implementation of the decision, and a score of $\geq 37.5$ signifies decision delay or feeling unsure about implementing their decisions [20]. This questionnaire is standard, and its validity and reliability have been confirmed in several studies. For instance, in a study conducted by Moudi, the reliability of this scale has been confirmed rendering a Cronbach's alpha coefficient of 0.92 and a correlation coefficient of 0.99 [18]. In the present study, the reliability of the questionnaire was confirmed by the internal consistency method rendering a Cronbach's alpha coefficient of 0.81 .

DRS is a five-item scale that measures regret after treatment decisions at a given point in time [21]. The participants respond to each item using a 5-point Likert scale ranging from 1 (strongly agree) to 5 (strongly disagree) [22]. Items 2 and 4 are reversely scored. The score of each item is subtracted from 1 and then multiplied by 25 . To obtain the final score, the items are summed and averaged. The final score falls within the range of 0 to100. A score of 0 means no regrets, while a score of 100 signifies high regret $[22,23]$. The validity and reliability of the abovementioned scale have been investigated in numerous studies. For example, in a study conducted by Moudi, reliability was confirmed with Cronbach's alpha coefficient of 0.94 and a correlation coefficient of 0.99 [18]. The reliability of the scale in the present study was confirmed by the internal consistency method rendering a Cronbach's alpha of 0.87 .

To select the samples, firstly, four centers were randomly selected from the community health centers of Torbat-e Jam. Considering that pregnant mothers in each of the centers may communicate with each other and be informed of the shared decision making and intervention, mothers in two centers were randomly assigned to the control group and their counterparts in the other two centers, who were similar to the subjects in the first center in terms of location and socioeconomic status, were allocated to the case group. Thereafter, using the pregnant mothers' registration system, eligible women with a previous cesarean section were listed and invited via phone call to participate in the study. A total of 86 eligible pregnant women who were willing to participate were included in the study. They were randomly assigned to intervention and control groups ( $n=43$ in each group).

Thereafter, mothers in the experimental group were provided with necessary information about the counseling session at the next visit (week 24-30). At weeks 2430 of gestation, demographic and fertility characteristics form as well as DCS were completed by pregnant mothers. In addition to routine care in both groups, the experimental group received a 90-min counseling session based on the three talk model of shared decision making [12] with the presence of the researcher, pregnant mother, spouse, and other people desired by the pregnant mother or her husband.

In the first stage (choice talk), the patient received the necessary information about the types of options (VBAC and repeated cesarean section). In the second stage (option talk), patients' information concerning the main options and participants' narratives were examined. In the third stage (decision talk), the pros, cons, risks, and family costs associated with each option were discussed, women with successful VBAC were interviewed, the couple's values/ preferences and concerns were talked over, and patients were supported to make a decision. If needed, more information was provided to mothers and their companions, and the final decision was left to mothers and their companions (Table 1). In the counseling session, apart from being provided with needed information, pregnant mothers were acquainted with the delivery department of Torbat-e Jam. After the first consultation session, other sessions were held if necessary. The counseling was conducted by a graduate student who was a midwife working in the delivery department and had received the necessary training on 
Table 1 Contents of two sessions of shared decision making (SDM) counseling

\begin{tabular}{|c|c|c|c|c|}
\hline $\begin{array}{l}\text { Stages of } \\
\text { three-talk } \\
\text { model of } \\
\text { SDM }\end{array}$ & Essential elements & Consultant responsibilities & & \\
\hline \multirow{2}{*}{$\begin{array}{l}\text { Stage } 1 . \\
\text { Choice talk }\end{array}$} & Problem presentation & \multicolumn{3}{|c|}{ According to the history of cesarean section, evaluation the mode of delivery in the current pregnancy } \\
\hline & Available options & \multicolumn{3}{|c|}{$\begin{array}{l}\text { It is time to think about what mode of delivery you will choose in the future: vaginal delivery or } \\
\text { cesarean section }\end{array}$} \\
\hline $\begin{array}{l}\text { Stage } 2 . \\
\text { Option talk }\end{array}$ & $\begin{array}{l}\text { Evaluation of mothers and } \\
\text { companions' information } \\
\text { regarding the mode of } \\
\text { delivery in women with } \\
\text { previous cesarean section }\end{array}$ & $\begin{array}{l}\text { Before making any decision, ask } \\
\text { them to explain their information } \\
\text { about the mode of delivery in } \\
\text { women with previous cesarean } \\
\text { section (Try to deeply understand } \\
\text { their main narrations) }\end{array}$ & $\begin{array}{l}\text { - Checking information } \\
\text {-Examining a clear } \\
\text { understanding of information } \\
\text { (Is their information correct or } \\
\text { misunderstood?) }\end{array}$ & $\begin{array}{l}\text { - Providing more information } \\
\text { - Answering questions } \\
\text {-Providing evidence if necessary }\end{array}$ \\
\hline \multirow[t]{5}{*}{$\begin{array}{l}\text { Stage } 3 . \\
\text { Decision } \\
\text { talk }\end{array}$} & $\begin{array}{l}\text { 1- Discussing the pros/cons } \\
\text { /risks/and family expenses }\end{array}$ & $\begin{array}{l}\text { Using participants' explanations } \\
\text { and narratives to understand and } \\
\text { extract points related to: physical, } \\
\text { psychological, financial, and social } \\
\text { impact of vaginal delivery/cesarean } \\
\text { section on both family and } \\
\text { newborn }\end{array}$ & $\begin{array}{l}\text { - Checking information } \\
\text {-Examining a clear } \\
\text { understanding of information } \\
\text { (Is their information correct or } \\
\text { misunderstood?) }\end{array}$ & $\begin{array}{l}\text {-Providing more information } \\
\text {-Answering questions } \\
\text {-Providing evidence if necessary } \\
\text {-Interviews with people with } \\
\text { successful vaginal birth after } \\
\text { cesarean section }\end{array}$ \\
\hline & $\begin{array}{l}\text { 2- Modification of values/ } \\
\text { preferences of mother and } \\
\text { companions }\end{array}$ & $\begin{array}{l}\text { Using the participant's explanations } \\
\text { and narratives to extract and clarify } \\
\text { what is most important to them. }\end{array}$ & $\begin{array}{l}\text { 1. Listing the most important } \\
\text { values, concerns, and worries } \\
\text { of mother and companions } \\
\text { 2. Helping them to have } \\
\text { accurate and realistic } \\
\text { preferences }\end{array}$ & $\begin{array}{l}\text {-The consultant helps them to } \\
\text { predict what they prefer to } \\
\text { happen in the future. Moreover, } \\
\text { how do they feel the short-term } \\
\text { and long-term consequences }\end{array}$ \\
\hline & $\begin{array}{l}\text { 3. Asking about mothers' } \\
\text { decisions and companions }\end{array}$ & $\begin{array}{l}\text { They are asked: } \\
\text { Are you ready to decide? } \\
\text { Or do you need more time? }\end{array}$ & $\begin{array}{l}\text { Sometimes they explicitly } \\
\text { need more time. The } \\
\text { counselor examines the } \\
\text { reasons and asks if they have } \\
\text { any further questions. } \\
\text { Are there any other things } \\
\text { that people have heard or } \\
\text { read about on the Internet } \\
\text { and should be discussed? }\end{array}$ & $\begin{array}{l}\text { 1.Providing an opportunity to talk } \\
\text { to a gynecologist about new } \\
\text { advances in delivery methods } \\
\text { 2- Presenting the opinion of the } \\
\text { American College of Obstetricians } \\
\text { and Gynecologists about the } \\
\text { method of delivery after cesarean } \\
\text { section } \\
\text { 3.Providing evidence if necessary }\end{array}$ \\
\hline & $\begin{array}{l}\text { 4. Discussing patient's abilities } \\
\text { and companions }\end{array}$ & $\begin{array}{l}\text { They are asked: } \\
\text { Are you sure you made up your } \\
\text { mind? }\end{array}$ & $\begin{array}{l}\text { Sometimes they delay the } \\
\text { decision. The counselor } \\
\text { should look into their reasons } \\
\text { and whether they have more } \\
\text { questions. }\end{array}$ & $\begin{array}{l}\text { 1.Providing more information } \\
\text { 2. Answering questions } \\
\text { 3.Providing evidence if necessary }\end{array}$ \\
\hline & 5. Follow-up & \multicolumn{3}{|l|}{$\begin{array}{l}\text { Follow-up } 8 \text { weeks after delivery to } \\
\text { review the decision }\end{array}$} \\
\hline
\end{tabular}

counseling. At the end of the session, each mother received a pamphlet on the advantages and disadvantages of VBAC. Moreover, the researcher's phone number was handed to the intervention group to contact the researcher in case they had any questions. Moreover, the researcher referred the pregnant mothers in the intervention group and their companions to one of the gynecologists in order to provide them with the necessary information to complete the consultation (second session) and answer their possible questions. At weeks 35-37 of gestation, DCS was completed in both intervention and control groups. In addition, DRS was completed for mothers in both groups 8 weeks after delivery in community health centers, and they were asked about the mode of delivery. The current study covered 24-30 weeks of gestation to two months after childbirth.

Data were analyzed in SPSS (version 19) using Chisquare, Mann-Whitney, Fisher's exact tests. $p$-value less than 0.05 was considered statistically significant.

CONSORT guidelines were adhered on reporting this clinical trial.

\section{Results}

During the study, four participants were excluded from the intervention group due to different reasons, including not attending counseling sessions $(n=2)$, delivery before the end of the intervention (preterm delivery) $(n=1)$, fetal indication for cesarean section (breech presentation at 35 weeks of pregnancy) $(n=1)$. Moreover, 
four cases were ruled out from the control group due to different reasons, including incomplete forms after delivery $(n=2)$, fetal indication for cesarean section (breech presentation at 36 weeks of gestation) $(\mathrm{n}=1)$, delivery before the end of the intervention (preterm delivery) $(\mathrm{n}=1)$. Finally, 78 people entered the study (Fig. 1).

The results of data analysis on the personal and midwifery characteristics of the participants demonstrated that the mean age of mothers in the SDM group and control group were $29.58 \pm 4.60$ years and $30.48 \pm 3.79$ years, respectively. The mean years of schooling of mothers in the SDM group and the control group were reported as $10.30 \pm 2.05$ and $11.38 \pm 3.86$ years, respectively. The mean of the inter-pregnancy interval in the SDM group and control group were $5.11 \pm 2.02$ and $5.74 \pm 2.71$ years. The mean number of pregnancies in the SDM and control group were reported as $3.02 \pm 1.22$ and $2.66 \pm 0.88$. The result of the Mann-Whitney test showed that there was no statistically significant difference between the two groups in terms of the abovementioned variables $(P>0.05)$. Other characteristics of the participants are presented in Table 2. The two groups were homogeneous regarding of confounding factors such as the type of previous cesarean section, the indication for previous cesarean section, wanted pregnancy and received pregnancy care.

Before the intervention, the mean total scores of decisional conflict in the SDM and control groups were obtained at $30.51 \pm 11.26$ and $28.41 \pm 15.01$, respectively, and no significant difference was observed between the groups $(P=0.29)$. Nonetheless, after the intervention, the mean total score of decisional conflict in the SDM group $(14.90 \pm 9.65)$ was significantly lower, as compared to that in the control group $(25.41 \pm 13.38)$. The scores of subscales (informed, values clarity, social support, uncertainty, and effective decision) were also significantly lower in the SDM group, in comparison to those obtained in the control group (Table 3).

Out of 24 mothers in the intervention group who were hospitalized for the trial of labor after cesarean, five mothers underwent emergency cesarean section due to lack of progress in delivery $(n=2)$, abnormal fetal heart rate $(\mathrm{n}=2)$ and meconium excretion in amniotic fluid $(n=1)$. In the control group, out of 11 mothers who

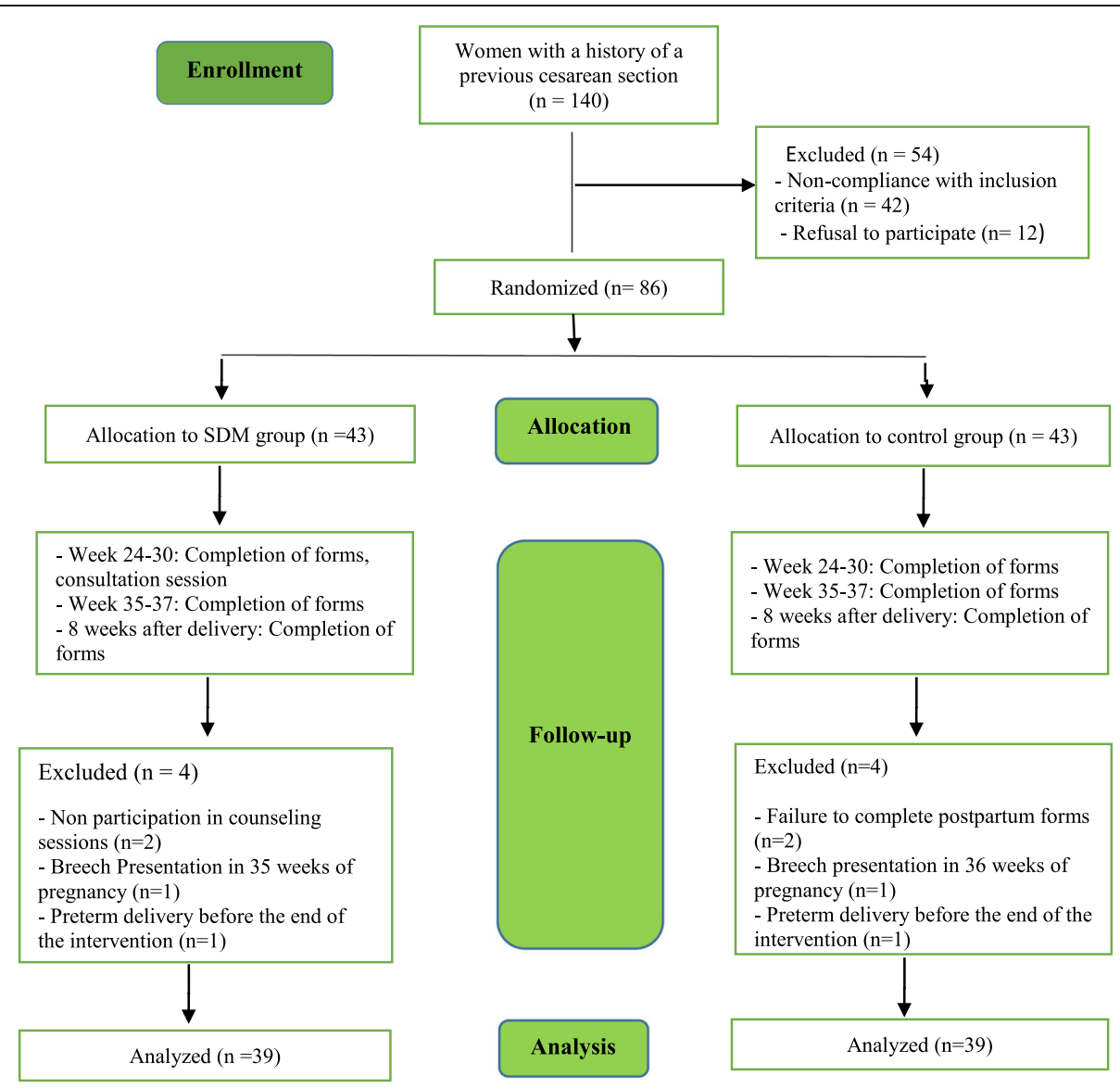

Fig. 1 Flowchart of study participants 
Table 2 Comparison of personal and midwifery characteristics of participants in SDM and control groups

\begin{tabular}{|c|c|c|c|c|c|}
\hline Characteristic & & $\begin{array}{l}\text { SDM group } \\
\mathrm{N}(\%)\end{array}$ & $\begin{array}{l}\text { Control group } \\
\mathrm{N}(\%)\end{array}$ & $\begin{array}{l}\text { Total } \\
\text { N (\%) }\end{array}$ & P-value* \\
\hline \multirow{5}{*}{ Occupation } & & & & & $327^{a}$ \\
\hline & Tousevilie & $29(14.3)$ & $20(00 . /)$ & $35(70.3)$ & 0.32 \\
\hline & Employee & $9(23.1)$ & $13(33.3)$ & $22(28.2)$ & \\
\hline & Laborer & $1(2.6)$ & $0(0)$ & $1(1.3)$ & \\
\hline & Total & $39(100)$ & $39(100)$ & $78(100)$ & \\
\hline \multirow[t]{3}{*}{ Previous cesarean section } & Emergency & $34(87.2)$ & $33(84.6)$ & $77(30.8)$ & $0.33^{\mathrm{a}}$ \\
\hline & Elective & $5(12.8)$ & $6(15.4)$ & $11(69.2)$ & \\
\hline & Total & $39(100)$ & $39(100)$ & $78(100)$ & \\
\hline \multirow[t]{6}{*}{ Indication of previous cesarean section } & Abnormal fetal presentation & $20(58.8)$ & $18(54.6)$ & $38(56.7)$ & $0.08^{\mathrm{a}}$ \\
\hline & Lack of labor progress & $7(20.6)$ & $8(24.2)$ & $15(22.4)$ & \\
\hline & Abnormal fetal heart rate & $4(11.8)$ & $6(18.1)$ & $10(14.9)$ & \\
\hline & Excretion of meconium in amniotic fluid & $1(2.9)$ & $1(3.1)$ & $2(3.0)$ & \\
\hline & Placenta Previa & $2(5.9)$ & $0(0.0)$ & $2(3.0)$ & \\
\hline & Total & $34(100)$ & $33(100)$ & $67(100)$ & \\
\hline \multirow[t]{3}{*}{ Wanted pregnancy } & Yes & $30(76.9)$ & $31(79.5)$ & $61(78.2)$ & $1.00^{\mathrm{b}}$ \\
\hline & No & $9(23.1)$ & $8(20.5)$ & $17(21.8)$ & \\
\hline & Total & $39(100)$ & $39(100)$ & $78(100)$ & \\
\hline \multirow[t]{3}{*}{ Regular pregnancy care } & Yes & $38(97.4)$ & 38 (97.4) & 76 (97.4) & $1.00^{\mathrm{b}}$ \\
\hline & No & $1(2.6)$ & $1(2.6)$ & $2(2.6)$ & \\
\hline & Total & $39(100)$ & $39(100)$ & $78(100)$ & \\
\hline
\end{tabular}

*Significance level: $P<0.05$

${ }^{a}$ Chi-squared test

${ }^{b}$ Fisher's exact test

Table 3 Comparison of decisional conflict and regret scores in SDM and control groups

\begin{tabular}{|c|c|c|c|c|}
\hline \multirow{2}{*}{$\begin{array}{l}\text { Decisional conflict } \\
\text { score }\end{array}$} & & \multirow{2}{*}{$\begin{array}{l}\text { SDM group } \\
\text { Mean }\left(\mathrm{SD}^{*}\right)\end{array}$} & \multirow{2}{*}{$\begin{array}{l}\text { Control group } \\
\text { Mean (SD) }\end{array}$} & \multirow[t]{2}{*}{$P$-value $* *$} \\
\hline & & & & \\
\hline \multicolumn{5}{|l|}{ Subscales } \\
\hline \multirow[t]{2}{*}{ Informed } & Before intervention & $29.04(8.51)$ & $30.98(17.93)$ & 0.54 \\
\hline & After intervention & $9.61(11.23)$ & $20.93(15.27)$ & 0.001 \\
\hline \multirow[t]{2}{*}{ Values clarity } & Before intervention & $32.47(16.75)$ & 32.69 (15.92) & 0.77 \\
\hline & After intervention & $19.65(13.31)$ & $27.54(17.10)$ & 0.03 \\
\hline \multirow[t]{2}{*}{ Social support } & Before intervention & $27.98(14.99)$ & $22.56(16.07)$ & 0.17 \\
\hline & After intervention & $8.33(10.46)$ & $16.66(12.82)$ & 0.002 \\
\hline \multirow[t]{2}{*}{ Uncertainty } & Before intervention & $31.67(17.67)$ & $26.54(17.76)$ & 0.18 \\
\hline & After intervention & $9.40(10.32)$ & $19.22(16.57)$ & 0.009 \\
\hline \multirow[t]{2}{*}{ Effective decision } & Before intervention & $30.82(19.26)$ & $25.80(17.74)$ & 0.28 \\
\hline & After intervention & $9.77(10.80)$ & $16.45(13.09)$ & 0.03 \\
\hline \multirow[t]{2}{*}{ Total score } & Before intervention & $30.51(11.26)$ & $28.41(15.01)$ & 0.29 \\
\hline & After intervention & $14.90(9.65)$ & $25.41(13.38)$ & $<0.001$ \\
\hline Decisional regret score & & $15.67(23.37)$ & 27. $30(26.75)$ & 0.007 \\
\hline
\end{tabular}


were hospitalized for the trial of labor, three mothers underwent emergency cesarean section due to lack of progress in delivery $(\mathrm{n}=2)$ and abnormal fetal heart rate $(\mathrm{n}=1)$. Finally, the results indicated that $19(48.7 \%)$ participants in the SDM group and $8(20.5 \%)$ cases in the control group gave birth vaginally. Chi-squared test denoted that there was a significant difference between the mode of delivery in the two groups $(P<0.001$; Table 4$)$.

The mean scores of decision regret two month after delivery were $15.76 \pm 23.37$ and 27. $30 \pm 26.75$ in the SDM and the control group, respectively. Furthermore, the results of the Mann-Whitney test revealed that there was a statistically significant difference between the two groups in terms of decision regret score $(P=0.007$; Table $3)$.

Regarding intra and postpartum complications, the results of the research showed that in the intervention group, there was one case of uterine dehiscence, two cases of postpartum hemorrhage, three cases of low neonatal Apgar score, two cases of infant hospitalization in the intensive care unit and one case of postpartum fever. In the control group, there was one case of postpartum hemorrhage, two cases of low neonatal Apgar score, two cases of infant hospitalization in the intensive care unit and two cases of postpartum fever. No maternal or fetal death was reported.

\section{Discussion}

As evidenced by the results of the present study, shared decision making, along with the use of pamphlets, reduced the total score of decisional conflict below the threshold of 25. In other words, mothers who attended SDM counseling sessions had lower decisional conflict about the mode of delivery. On the other hand, they had a greater awareness of the benefits and risks of delivery modes, social support, and appropriate decision making. Furthermore, individual values were taken into account to a greater extent in decision making.

This finding assumes great significance since decisional conflict causes people to change their minds, delay their decision, and make decisions with undesirable outcomes $[17,18]$ and regret [24]. Based on the results of a study carried out by Shorten et al. (2005), the intervention group who received decision aid showed a reduction in decisional conflict, compared to the control group [25].

Montgomery et al. (2007) performed a study to assess the effects of two computer-based decision aids on decisional conflict and mode of delivery in women with a previous cesarean section. The results of the mentioned study illustrated that there was less decisional conflict in the intervention group, compared to that in the control group, and the difference between them was significant [26]. In a study conducted by Eden et al. (2014), the use of decision tools (decision aids or brochures) helped women reduce conflict over birth decisions. These products provide the needed information about the benefits and risks of modes of delivery; nonetheless, they differ in the format and level of risk detail [27]. The results of a study performed by Moudi et al. (2018) indicated that the total score of decisional conflict, as well as the scores of subscales (informed, values clarity, social support, uncertainty, and effective decision), were significantly lower in the intervention group, compared to those obtained in the control group [18]. The findings of the present study are in line with those obtained in the aforementioned studies. Therefore, it can be stated that shared decision making increases the knowledge of pregnant women and their husbands, answer their questions, and involve them in the decision making process. Therefore, it is effective in the reduction of decisional conflict, enhancement of decision making quality, and ease of making this choice among the available options. In a study conducted by Kuppermann et al. (2020), patientcentered decision support tools had no effect on decisional conflict [28]. The results of the referred study are inconsistent with the findings reported in the present study. This difference can be ascribed to the gestational age when the intervention was performed. In the mentioned study, the intervention was performed before the 25th week of pregnancy, while it was conducted after the 25th week in the present study. Moreover, in the stated study, most of the participants had higher education and there was relatively high rate of trial of labor in

Table 4 Comparison of the trial of labor and mode of delivery in SDM and control groups

\begin{tabular}{|c|c|c|c|c|c|c|}
\hline \multirow{2}{*}{\multicolumn{2}{|c|}{ Variable }} & & \multirow{2}{*}{$\begin{array}{l}\text { SDM group } \\
\mathrm{N}(\%)\end{array}$} & \multirow{2}{*}{$\begin{array}{l}\text { Control group } \\
\mathrm{N}(\%)\end{array}$} & \multirow{2}{*}{$\begin{array}{l}\text { Total } \\
\text { N (\%) }\end{array}$} & \multirow[t]{2}{*}{ P-value ${ }^{a}$} \\
\hline & & & & & & \\
\hline \multicolumn{3}{|c|}{ Trial of labor after cesarean (yes) } & $24(61.5)$ & $11(28.2)$ & $35(44.8)$ & $<0.001$ \\
\hline \multirow[t]{3}{*}{ Mode of delivery } & VBAC ${ }^{c}$ & & $19(48.7)$ & $8(20.5)$ & $27(34.6)$ & $<0.001$ \\
\hline & $\mathrm{RCS}^{\mathrm{d}}$ & Emergency & $5(12.8)$ & $3(7.7)$ & $8(10.3)$ & \\
\hline & & Elective & $15(38.5)$ & $28(71.8)$ & $43(55.1)$ & \\
\hline
\end{tabular}

${ }^{\mathrm{a} S}$ Significance level: $\mathrm{P}<0.05$

${ }^{a}$ Chi-squared test

'Vaginal birth after cesarean

${ }^{\mathrm{d}}$ Repeated cesarean section 
both randomization groups. Furthermore, tablet-based decision aids were used in the abovementioned study, whereas in the present study, face-to-face consultation was conducted. Various formats, such as pamphlets, interactive media, video, or audio-tapes are not a good substitute for physician consultation. Moreover, face-toface consultation offers a wide range of possibilities for discussion, information exchange, and effective supportive interventions. This explanation highlights the effectiveness of our counseling in the reduction of decisional conflict. Furthermore, face-to-face counseling based on shared decision making opens up the possibilities of information provision, communication, and discussion even for people with low literacy. McCaffrey et al. (2007) in their systematic review of patient decision making tools reported that patients and physicians who used decision aids made better decisions. Patients with more involvement in treatment decisions were more informed about their options and had more realistic expectations about what might happen; moreover, the majority of them selected the option that was most valuable to them and better suited to their conditions [14].

Based on the results of the present study, shared counseling increased the rate of VBAC so that there was a significant difference between the mode of delivery in the two groups. Hamilton et al. (2016) noted that a good medical decision is achieved with a good decision making process [29]. The findings of a study carried out by Wise et al. (2019) indicated that women who were initially uncertain about their preferred mode of delivery showed a greater reduction in decisional conflict score after receiving additional decision aid and were more likely to plan for VBAC [30]. However, inconsistent with the findings of the present research, the results of the study conducted by Kuppermann et al. (2020) on the effect of a patient-centered decision support tool revealed that the rate of vaginal delivery was not significantly different between the intervention and control groups [28]. This discrepancy in results can be attributed to the gestational age when the intervention was performed. In the abovementioned study, the intervention was performed before the 25th week of pregnancy, while it was conducted after the 25 th week in the present study.

In the present study, the level of decision regret in the first month after delivery was lower in mothers who participated in SDM counseling sessions. This finding is significant since regret weakens the intention to repeat the same choice [18].

Although birth usually ends in a positive outcome, many women experience negative emotions [31], especially when their delivery is not as expected [32]. Negative experiences before, during, or following decisions about treatment measures can lead to regret about the choices that were made [22]. The results of a study conducted by Becerra-Perez et al. (2016) showed that most patients who received primary care indicated mild regrets about the decision and experienced more regrets in the event of decisional conflict [17]. The findings of the stated study are in compliance with the present study, the intervention group who received shared counseling along with the pamphlet reported less decisional conflict and regret. In a study conducted by Konheim-Kalkstein et al. (2019) entitled "Regrets from women with an unplanned cesarean delivery", the results illustrated that $73 \%$ of women expressed a feeling of regret after childbirth, and only emotional support was accompanied by less regret [33]. In agreement with the present research, in the study by Moudi et al. (2018), at 1-month post-abortion, the regret score was low which can be ascribed to the pre-abortion counseling session, as well as shared decision making [18]. Ghiasvandian et al. (2013) carried out a study on the effect of decision aids on decision regret in patients with breast cancer after 8 weeks of treatment. The results denoted that there was no statistically significant difference between the two groups in terms of regret. It can be attributed to the short follow-up duration after treatment initiation which did not allow for tracking the positive or negative effects of this choice (the type of treatment) on quality of life and health consequences of patients during this short period [34]. The results of the mentioned study are not consistent with those obtained in the present study.

The notable strengths of the present study include the use of shared counseling for mothers with previous cesarean sections who were a sensitive group in need of counseling process, the creation of great opportunities for mothers with successful VBAC to attend counseling sessions, and the presence of pregnant women's relatives in counseling sessions. On the other hand, the current study had several limitations. The First limitation was the unpredictability of healthy pregnant women to continue participating in the study due to prenatal problems and exclusion from the study. Secondly, due to the nature of the study and the fact that the intervention and data collection was performed by one of the authors, it was not possible to blind the participants and the data collector. Thirdly, it was not possible to use a larger sample size due to time constraints. Fourthly, although the content of the decision aid was carefully designed so as not to advocate from a particular delivery method and the researchers also paid attention to this point during the consultation, but counselor bias during the directed counseling was one of the limitations of the study.

\section{Conclusion}

The overall results of the present study demonstrated that SDM counseling sessions increase awareness, value 
clarity, as well as decision support. In so doing, it can be of great help in the reduction of decisional conflict and regret, as well as the rate enhancement of VBAC. In other words, shared decision making helps counselors engage mothers and spouses in a thoughtful discussion so that they can make a realistic and defensible decision with the least likelihood of regret. Therefore, this counseling method can be used in prenatal care to reduce the rate of repeated cesarean section.

\section{Abbreviations}

VBAC: Vaginal birth after cesarean; TOLAC: Trial of labor after cesarean; RCS: Repeated cesarean section; SDM: Shared decision making;

DCS: Decisional conflict scale; DRS: Decision regret scale

\section{Acknowledgements}

The authors' deepest appreciation goes to the staff of community health centers of Torbat-e Jam for their cooperation in implementing the project. Special gratitude is also extended to all the pregnant mothers and their spouses who participated in this study.

\section{Authors' contributions}

FHT, FGH, and RR designed the study. FGH collected data. FHT and FM analyzed and interpreted the data. FHT and RR wrote and revised the paper. All authors read and approved the final manuscript.

\section{Funding}

The current article is extracted from a master's thesis in midwifery education which was conducted with the financial support of the Research Deputy of Gonabad University of Medical Sciences, Iran. Research Deputy had no role in the design of the study and collection, analysis, and interpretation of data and in writing the manuscript.

\section{Availability of data and materials}

Additional information is not available to maintain confidentiality.

\section{Ethics approval and consent to participate}

The current study was approved by the ethics committee of Gonabad University of Medical Sciences (IR. GMU. REC.1397.132) and registered in Iranian Registry of Clinical Trials (IRCT20190506043499N1). Informed written consent was obtained from all participants. Furthermore, confidentiality of personal information, explanation of the research process and participants' right to withdraw from the study were observed at each stage.

\section{Consent for publication}

Not applicable.

\section{Competing interests}

The authors declare that they have no competing interests.

\section{Author details}

${ }^{1}$ Department of Midwifery, Faculty of Medicine, Social Development \& Health Promotion Research Center, Gonabad University of Medical Sciences, Gonabad, Iran. ${ }^{2}$ Student Research Committee, Faculty of Medicine, Gonabad University of Medical Sciences, Gonabad, Iran. ${ }^{3}$ Department of Epidemiology \& Biostatistics, School of Health, Social Development and Health Promotion Research Center, Gonabad University of Medical Sciences, Gonabad, Iran.

Received: 7 September 2020 Accepted: 3 February 2021

Published online: 17 February 2021

\section{References}

1. Denham SH, Humphrey T, de Labrusse C, Dougall N. Mode of birth after caesarean section: individual prediction scores using Scottish population data. BMC Pregnancy Childbirth. 2019;19(1):84. https://doi.org/10.1186/s12 884-019-2226-6.

2. Bonzon M, Gross MM, Karch A, Grylka-Baeschlin S. Deciding on the mode of birth after a previous caesarean section - an online survey investigating women's preferences in Western Switzerland. Midwifery. 2017:50:219-27. https://doi.org/10.1016/j.midw.2017.04.005.

3. Vankan E, Schoorel E, van Kuijk S, Nijhuis J, Hermens R, Scheepers H, et al. The effect of the use of a decision aid with individual risk estimation on the mode of delivery after a caesarean section: a prospective cohort study. PLoS ONE. 2019;14(9):e0222499. https://doi. org/10.1371/journal.pone.0222499.

4. Lundgren I, Morano S, Nilsson C, Sinclair M, Begley C. Cultural perspectives on vaginal birth after previous caesarean section in countries with high and low rates - a hermeneutic study. Women Birth. 2020;33(4):e339-47. https:// doi.org/10.1016/j.wombi.2019.07.300.

5. MJK O. Recent trends in vaginal birth after cesarean delivery: United States, 2016-2018. NCHS data brief, no 359. Hyattsville: National Center for Health Statistics; 2020.

6. U.S. Department of Health and Human Services, Office of Disease Prevention and Health Promotion. Healthy People. Washington, D.C: Maternal, infant, and child health; 2020. Available from: https://www.hea Ithypeople.gov/2020/topics-objectives/topic/maternal-infant-and-child-hea Ith/objectives

7. Attanasio LB, Kozhimannil KB, Kjerulff K. Women's preference for vaginal birth after a first delivery by cesarean. Birth. 2018;46(1):1-10. https://doi. org/10.1111/birt.12386

8. Schoorel ENC, Vankan E, Scheepers HCJ, Augustijn BC, Dirksen CD, De Koning M, Van Kuijk SM, Kwee A, Melman S, Nijhuis JG, Aardenburg R. Involving women in personalised decision-making on mode of delivery after caesarean section: the development and pilot testing of a patient decision aid. BJOG Int J Obstet Gynaecol. 2014;121(2):202-9.

9. Shorten A, Shorten B, Fagerlin A, Illuzzi J, Kennedy HP, Pettker C, et al. A study to assess the feasibility of implementing a web-based decision aid for birth after cesarean to increase opportunities for shared decision making in ethnically diverse settings. J Midwifery Womens Health. 2019;64(1):78-87. https://doi.org/10.1111/jmwh.12908.

10. Adams JR, Drake RE. Shared decision making and evidence - based practice. Community Ment Health J. 2006;42(1):87-105.

11. Hong P, Gorodzinsky AY, Taylor BA, Chorney JM. Parental decision making in pediatric otoplasty: the role of shared decision making in parental decisional conflict and decisional regret. Laryngoscope. 2016;126(Suppl 5):513. https://doi.org/10.1002/lary.26071.

12. Elwyn G, Frosch D, Thomson R, Joseph-Williams N, Lloyd A, Kinnersley P, et al. Shared decision making: a model for clinical practice. J Gen Intern Med. 2012;27(10):1361-7. https://doi.org/10.1007/s11606-012-2077-6.

13. Mostafaie H, Parniyanfard N, Ghojazadeh M, Pourmalek A, Madanlou K, Abbaspour M, et al. Shared decision making and Its Correlation with Demographic Characteristics of Iranian Patients. J Adv Medicine Med Res. 2014;4(16):3140-7. https://doi.org/10.9734/BJMMR/2014/8841.

14. McCaffery K, Irwig L, Bossuyt P. Patient decision aids to support clinical decision making: evaluating the decision or the outcomes of the decision. Med Decis Mak. 2007;27(5):619-25. https://doi.org/10.1177/0272989X07306787.

15. Graham ME, Westerberg BD, Lea J, Hong P, Walling S, Morris DP, et al. Shared decision making and decisional conflict in the Management of Vestibular Schwannoma: a prospective cohort study. J Otolaryngol Head Neck Surg. 2018;47(52). https://doi.org/10.1186/s40463-018-0297-4.

16. Thompson-Leduc $P$, Turcotte $S$, Labrecque M, Légaré F. Prevalence of clinically significant decisional conflict: an analysis of five studies on decision making in primary care. BMJ Open. 2016;6:e011490. https://doi. org/10.1136/bmjopen-2016-011490.

17. Becerra-Perez MM, Menear M, Brehaut JC, Légaré F. Extent and predictors of decision regret about health care decisions: a systematic review. Med Decis Mak. 2016;36(6):777-90. https://doi.org/10.1177/0272989X16636113.

18. Moudi Z, Phanodi Z, Ansari H, Zohour MM. Decisional conflict and regret: shared decision making about pregnancy affected by $\beta$-thalassemia major in southeast of Iran. J Hum Genet. 2018;63(3):309-31.

19. Makoul G, Clayman ML. An integrative model of shared decision making in medical encounters. Patient Educ Couns. 2006;60:301-12.

20. O'Connor AM. Validation of a decisional conflict scale. Med Decis Mak. 1995; 15(1):25-30.

21. O'Conner, A. User manual-decision conflict scale (2010). Available from: https://decisionaid.ohri.ca/docs/develop/User_Manuals/UM_Decisional_ Conflict.pdf

22. Brehaut J, O'Conner A, Wood T, Hack T, Siminoff L, Gordon E, et al. Validation of a decision regret scale. Med Decis Mak. 2003;23(4):281-92. 
23. O'Conner, A. User manual-decisional regret scale (1996). Available from: http:// decisionaid.ohri.ca/docs/develop/User_manuals/UM_Regret_Sca le. pdf. Accessed 1 July 2017.

24. Toohill J, Fenwick J, Gamble J, et al. A randomized controlled trial of a psycho-education intervention by midwives in reducing childbirth fear in pregnant women. Birth. 2014;41(4):384-94. https://doi.org/10.1111/ birt.12136.

25. Shorten A, Shorten B, Keogh J, West S, Morris J. Making choices for childbirth: a randomized controlled trial of a decision-aid for informed birth after cesarean. Birth. 2005;32(4):252-61. https://doi.org/10.1111/j.0730-7659.2 005.00383.X.

26. Montgomery AA, Emmett CL, Fahey T, et al. Two decision aids for mode of delivery among women with previous caesarean section: randomised controlled trial. BMJ. 2007;334(7607):1305. https://doi.org/10.1136/bmj.39217. 671019.55.

27. Eden KB, Perrin NA, Vesco KK, Guise JM. A randomized comparative trial of two decision tools for pregnant women with prior cesareans. J Obstet Gynecol Neonatal Nurs. 2014;43(5):568-79.

28. Kuppermann M, Kaimal AJ, Blat C, et al. Effect of a patient-centered decision support tool on rates of trial of labor after previous cesarean delivery: the PROCEED randomized clinical trial. JAMA. 2020;323(21):2151-9. https://doi. org/10.1001/jama.2020.5952.

29. Hamilton JG, Lillie SE, Alden DL, Scherer L, Oser M, Rini C, et al. What is a good medical decision? A research agenda guided by perspectives from multiple stakeholders. J Behav Med. 2017;40(1):52-68. https://doi.org/10.1 007/s10865-016-9785-z

30. Wise MR, Sadler L, Shorten B, van der Westhuizen K, Shorten A. Birth choices for women in a 'Positive birth after Caesarean' clinic: randomised trial of alternative shared decision support strategies. Aust N Z J Obstet Gynaecol. 2019;59(5):684-92. https://doi.org/10.1111/ajo.12955.

31. Aragon M, Chhoa E, Dayan R, et al. Perspectives of expectant women and health care providers on birth plans. J Obstet Gynaecol Can. 2013;35(11): 979-85.

32. Mei JY, Afshar Y, Gregory KD, et al. Birth plans: what matters for birth experience satisfaction. Birth. 2016;43(2):144-50.

33. Konheim-Kalkstein YL, Miron-Shatz T. "If only I had ... ".: Regrets from women with an unplanned cesarean delivery. J Health Psychol. 2019; 1359105319891543. https://doi.org/10.1177/1359105319891543.

34. Ghiyasvandian S, Mousavizadeh SN, Dehghan Nayeri N, Haghani H. The effect of decision Aid's Pakage in selected treatment by patients with early stage breast Cancer and decision making outcomes. J Fasa Univ Med Sci. 2013;3(3):271-9.

\section{Publisher's Note}

Springer Nature remains neutral with regard to jurisdictional claims in published maps and institutional affiliations.

Ready to submit your research? Choose BMC and benefit from:

- fast, convenient online submission

- thorough peer review by experienced researchers in your field

- rapid publication on acceptance

- support for research data, including large and complex data types

- gold Open Access which fosters wider collaboration and increased citations

- maximum visibility for your research: over $100 \mathrm{M}$ website views per year

At BMC, research is always in progress.

Learn more biomedcentral.com/submissions 